$\xi=-1$

\title{
Opening theory as an innovative model of the development strategy of industrial companies
}

\author{
O. Arefyeva ${ }^{1}$, V. Prokhorova ${ }^{2}$, N. Chebanova ${ }^{3}$, V. Khaustova ${ }^{4}$, S. Mushnikova ${ }^{5}$ \\ ${ }^{I}$ National Aviation University, Ukraine \\ ${ }^{2}$ Ukrainian Engineering and Pedagogical Academy, Ukraine \\ ${ }^{3}$ Ukrainian State University of Railway Transport, Ukraine \\ ${ }^{4}$ Research and Development Centre for Industrial Problems of Development of the NAS of Ukraine, Ukraine \\ ${ }^{5}$ National Metallurgical Academy of Ukraine, Ukraine \\ *Corresponding author E-mail: vkprohkorova@gmail.com
}

\begin{abstract}
The modern state of the national economy requires significant changes at all levels. Industrial companies as one of the main elements of the national economy exert a great influence on formation of the well-being. So, it is industrial companies that should be developed. However, development is only possible provided there is a relevant control system, and in the modern economic conditions, innovative management forms and techniques for the development of industrial companies should be implemented. Together with multiple current management forms and techniques for industrial companies, implementing an innovative form that is based on opening theory borrowed from the chess game is proposed. Using this theory that unites mathematical and gaming methods of the management of development of an industrial company, an innovative model of the development strategy could be formed that would take into account antagonisms of socioeconomic relations. Opening theory has distinct advantages in the formation of the innovative development strategy for an industrial company. It takes into account multiples factors which influence the contradictions in the socioeconomic relations choosing the optimal decision by the min antagonism criterion in the initial phase. A material deficiency of the mathematical formalization of the socioeconomic problems is the result of their qualitative novelty and complexity.
\end{abstract}

Keywords: game theory, opening, opening theory, innovative form, development of an industrial company, development strategy

\section{Introduction}

The modern state of functioning of economic actors and first of all, industrial companies, is in the difficult recessionary conditions. Both external and internal factors influence the performance of the companies in different ways and have both negative and positive consequences.

Any development assumes occurrence of various contradictions between the subjects of socioeconomic relations (antagonism of relations). It refers to all subjects of the socioeconomic relations at any level of the economy: be it a producer and a consumer, a businessman and governmental authorities, governmental authorities of different countries etc. The present-day conditions claim to search for new forms of management, particularly, for industrial companies as actors of the real economy, the performance of which mainly defines the national well-being and the well-being of every individual [2].

Development of an industrial company requires forming a strategy that should be aimed at flexible changes to increase their competitiveness. Prediction of trends of development (direction vector) in conditions of ambiguity is one of the most difficult processes. An essential factor to improve efficiency of development management of industrial companies is using innovative forms of the management strategy with gaming techniques, mathematical models and methods in preparing and making managerial decisions.

\section{Main Body}

Difficult socioeconomic conditions of the industrial companies are caused by external and internal factors and destabilize their activities. Imperfect regulatory environment, disproportionate taxation system, undeveloped outer production infrastructure, as well as ineffective financial planning and assets management, high level of obsolescence and depreciation of the manufacturing facilities of industrial companies, inability to conduct timely internal diagnosing of negative trends in their activities, required the to form a system of innovative management forms for industrial companies and their adjustment to the current functioning conditions.

There is fairly numerous different innovative forms of management of the complex socioeconomic systems to which industrial companies belong. They include:

- controlling - provision of significant information for the management system;

- re-engineering, which allows for radical transformation of business process and system of control;

- systemic intervention strategy - ordering and securing the systemic approach to the management, etc.

The above forms of the innovative management are aimed at achieving short-term and long-range purposes of the business activity. The prerequisite for the successful performance is beginning of formation of socioeconomic relations between different subjects and possible results of their interaction [3]. 


\subsection{General Provisions of the Opening Theory}

The opening phase of development strategy formation encounters a number of factors that prevent from choose one of the best variants to get positive result in case of unforeseeableness. That is, a variety of cause-and-effect relationships appears which require composing a few alternative options of case scenario under different economic conditions, with different level of antagonistic influence of participants of these events. In such conditions using the latest innovative management forms for the development of industrial companies becomes necessary, one of which is, in our opinion, opening theory at the stage of formation of the development strategy.

Opening theory originates from the initial stage of chess. It provides for quick safe predictable sequence of events and characterizes the capacity of players. The most brisk development of the opening theory, creation of totally new principles and their major options occurred before the 20th century in the times of evolution of chess as a game. By the second half of the 20th century exploring of the debuts in the chess reduced to the overview of the certain variants that appear certain already known initial stages, but over the last years development of the opening theory in chess has practically ceased. After the several centuries of development of the opening theory and due in no small part to appearance of powerful computers and high-qualitative chess applications, opening has become rather least creative part of all in the chess game. All major options have been addressed comprehensively, sometimes up to $15^{\text {th }}$ or $20^{\text {th }}$ move, and in some cases even further [4].

However, using opening theory as the variety of the game theory in the revolutionary development management of the socioeconomic systems has the corresponding foundation and is one of the innovative management forms. This refers primarily to quick safe development of performance of companies as socioeconomic systems, which is related to mobilization of efforts of participants of socioeconomic relations as players in the market in different economic conditions. Comparative analysis of elements of the opening theory in chess and in socioeconomic relations is given in the Table below.

Table: Comparative analysis of elements of the opening theory

\begin{tabular}{|c|c|}
\hline \multicolumn{2}{|c|}{ Elements of the opening theory: } \\
\hline chess & socioeconomic relations \\
\hline - quick development & $\begin{array}{l}\text { - quick safe development of the } \\
\text { socioeconomic system }\end{array}$ \\
\hline - control of the centre & $\begin{array}{l}\text { - routine and real-time monitoring } \\
\text { of the activity }\end{array}$ \\
\hline - king safety & $\begin{array}{l}\text { - safe adjustment of activity during } \\
\text { the development }\end{array}$ \\
\hline $\begin{array}{l}\text { Counteracting to the opponent's } \\
\text { plans }\end{array}$ & $\begin{array}{l}\text { Avoiding conflict situations } \\
\text { (minimizing antagonisms) }\end{array}$ \\
\hline $\begin{array}{l}\text { connection of the plan of the game } \\
\text { with middlegame and endgame }\end{array}$ & $\begin{array}{l}\text { connection with the current activity } \\
\text { of the socioeconomic system aimed } \\
\text { at the positive result }\end{array}$ \\
\hline
\end{tabular}

Participants of the chess game are two players who have a contradiction: each one's goal is winning. Principal players of the market are subjects of the socioeconomic relations: industrial companies, suppliers, consumers, financial institutions, governmental organizations and institutes etc. Functioning of each of these subjects has specific interest. Mutual relations between different subjects of the market (players) are nearly always accompanied by different antagonisms (contradictions) of functioning in the market. In the chess, the foundation of opening is the first move of a piece, on which further course of the chess game depends, while in the socioeconomic relations, the first step is determination of the objective of the development, subjects of the relations and, on the basis of estimated antagonisms, choosing one strategy from the variety of the alternatives.

During the entire course of a chess game, the centre and king, as the weakest piece, are controlled. In the activities of the socioeconomic systems, the core business is one of the weakest elements. Therefore during the organization and implementation of the development strategy, on the basis of the routine and realtime monitoring of activities, measures should be developed on security and relevant adjustment of functioning of the socioeconomic system to eventual challenges and changes of the economic conditions.

In chess, possibility of the consequent defence of the pieces and as a result, counteracting to the opposition, depends on the chosen opening (first move). This in its turn influences the middlegame in which the key part of the chess game generally develops - attack and defense, positional maneuvering, combinations and sacrifices. This part is characterized by a large number of pieces and the variety of game plans. Sometimes a chess play game misses this part and goes over to endgame at once. Middlegame of an industrial company is its daily operations on which eventual performance of the company depends. At this stage, more attention should be given to minimizing the antagonisms between the players of the socioeconomic relations.

\subsection{Opening Theory in the Innovative form of the Development Strategy of the Industrial Company}

Today, the specific features of using the game theory and the opening theory as a variety thereof is induced by a number of factors, such as indeterminate and unstable economic and political situation in the country; sustaining financial and economic crisis and more, which in turn influences functioning of industrial companies, making strategic and tactical decisions. The development strategy of an industrial company on the basic of opening theory may be represented as a complex process that can be implemented in several stages (Fig. 1). 
Step 1

Step 2
Step 3

Step 4

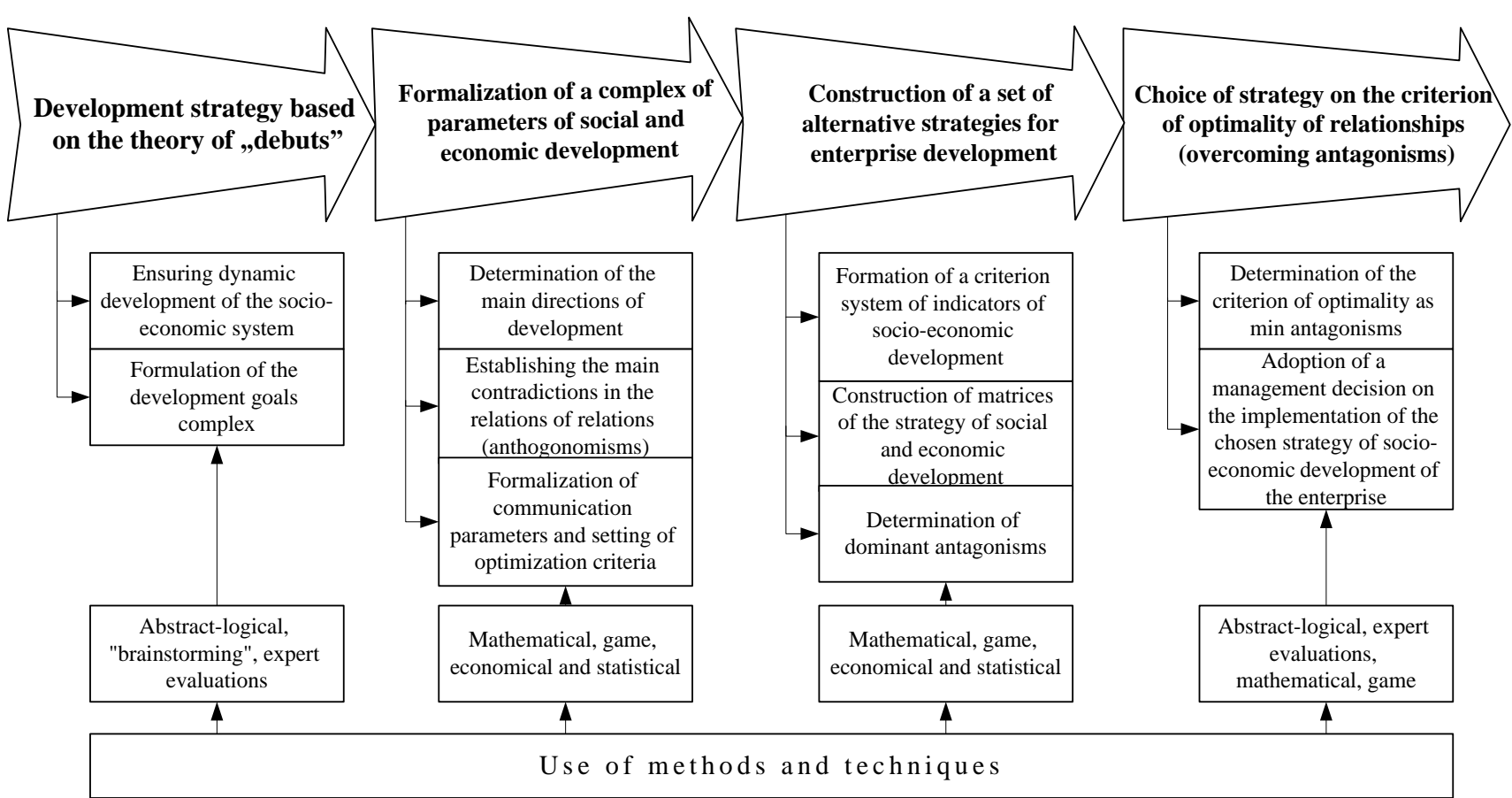

Fig. 1: Stages of formation of the development strategy on the basic of the opening theory

Opening of the "game" and one of the main phases of formation of the development strategy of the industrial company is objective statement and determination of the operation trends. To ensure quick development of the socioeconomic relations, a complex of the interrelated objectives and challenges that affect every element of the system should be established. Such level of processing imposes very serious demands to the preparation of opening by managers - even managers with minimal qualification must learn major options which are most common in this issue. Any professional manager today just cannot "play" successfully without knowing all openings that are used in practice as a set of basic cases and learn at least some of them thoroughly. This phase will be successful when abstract logical methods and decisionmaking techniques, such as expert evaluations, "brain storms", "objectives tree" etc. are used.

An important element of the development management for an industrial company that ensures successful sequence of events and managerial decision-making is phase of the formalization of complex indicators socioeconomic development. All socioeconomic relations can be formalized (written in mathematical expressions) in one form or another. Using opening theory as a game provides for formation of an idealized mathematic model of collective behavior with a defined number of "players" (participants) who affect the situation (result of the game), although their interests (their gains in different possible situations) differ. Antagonism of the players' interests causes a conflict, while coincidence of wants makes the "game" pure coordination for which cooperation is the only logical behavior [1]. In most socioeconomic relations, which arise from different situations, interests of «players» are neither strictly antagonistic nor coincide. Therefore establishment of the optimization criterions for the behavior of each of them is the basis for formation of alternative development strategy for an industrial company.

\subsection{Formalization of Antagonisms in a Development Strategy Model}

The next stage of forming a strategy model for the development of an industrial company is the construction of a set of alternative strategies. The main tools for implementing this stage are game techniques, which are understood as a set of logical and mathematical and statistical techniques and procedures aimed at receiving from experts the information necessary to prepare and select optimal decisions. They are used in situations where the choices, rationale and evaluations of the consequences of decisions cannot be made on the basis of accurate calculations. This directly refers to the formation of a multi-criteria system of indicators of socioeconomic development with the subsequent using them in the construction of strategy matrixes with the definition of the dominant antagonisms of the socioeconomic relations between the "players".

Using game, mathematical, including matrix methods in formation of the development strategy model, we define the main assumptions:

- In simple (one move) games, when a one-time antagonistic relationship occurs between the "players", the concepts of a strategy and a possible action coincide. In this case, the complex the player's of strategies covers all their possible actions, and any action possible for the player is their strategy. In complex (multimove games), the concepts of "options for a possible actions" and "strategies" may differ.

- the player's strategy is considered to be optimal, if it provides the player with the maximum possible average gain or the least possible average loss, regardless of the strategy used by the opponent, in case of multiple repetition of the game;

- the strategy that provide the maximum gain may lack another important representation of optimality, i.e. stability (equilibrium) of the solution. Solutions of the game are stable (equilibrium), if the strategies corresponding to this solution form a situation which none of the players is interested to change.

Thus, each of the two players intends to perform an action. In this case, circumstances are often such that, firstly, performing this 
action is expedient, for example, as later as possible, and secondly, it is desirable to prevent by its action that of the opponent. Such a conflict in the presence of the opposite interests of its parties is natural to be simulated by an infinite antagonistic game on a unit square, in which the function of gain $\boldsymbol{H}$ in the general case has the form:

$$
\left.\begin{array}{l}
\psi(x, y), \text { at } x<y \\
\varsigma(x), \text { at } x=y \\
\varphi(x, y), \text { at } x>y
\end{array}\right\}
$$

Where each of functions $\psi$ and $\varphi$

a) is continuous for both variables;

б) monotonically increases on $\boldsymbol{x}$ at any $\boldsymbol{y}$ value;

в) monotonically decreases on $\boldsymbol{y}$ at any $\boldsymbol{x}$ value;

г) fulfils the condition

$$
\varphi(x, x) \leq \varsigma(x) \leq \psi(x, x)
$$

If the matrix of the game has a saddle point, then its solution is immediately found by the maximin principle.

A question of determining the result of the game arises if the payment matrix has no saddle point. Applying the maximin principle by each player provide for player $\boldsymbol{A}$ gain of at least $\boldsymbol{\alpha}$, while player $\boldsymbol{B}$ loses not more than $\beta$. Given that $\alpha<\beta$, it natural for Player $\boldsymbol{A}$ to wish to increase the gain, while for Player $\boldsymbol{B}$ - to reduce the loss. Searching for such a solution makes it necessary to apply alternative strategies: alternate pure strategies with some frequencies.

A random term the values of which are the player's pure strategies, is its alternative strategy. Thus, the task of the player's alternate strategy is to indicate the probabilities with which their pure strategies are selected.

Then let us denote alternative strategies of Players $\boldsymbol{A}$ and $\boldsymbol{B}$, respectively

$\mathrm{S}_{\mathrm{A}}=\left\|\mathrm{p}_{1}, \mathrm{p}_{2}, \ldots, \mathrm{p}_{\mathrm{m}}\right\|$,

$\mathrm{S}_{\mathrm{B}}=\left\|\mathrm{q}_{1}, \mathrm{q}_{2}, \ldots, \mathrm{q}_{\mathrm{n}}\right\|$,

where $\mathrm{p}_{\mathrm{i}}-$ probability of using the pure strategy by Player $\boldsymbol{A}$

$$
\boldsymbol{A}_{i} ; \sum_{i=1}^{m} p_{i}=1
$$

$\mathrm{q}_{\mathrm{j}}$ - probability of using the pure strategy by Player $\boldsymbol{B}$

$$
\boldsymbol{B}_{\mathrm{j}} ; \sum_{j=1}^{n} q_{j}=1 .
$$

In an individual case, when all probabilities, except one, are zero, and this one is one, the alternative strategy turns into a pure one.
Alternative strategies are used in cases when the game repeats many times, but in each case the player uses different pure strategies with relevant frequencies of their use, being $\boldsymbol{p i}$ and $\boldsymbol{q j}$. Alternative strategies in the game theory are models of variable, flexible tactics, when neither player knows what strategy the opponent will choose in this game [1].

If Player $\boldsymbol{A}$ uses an alternative strategy:

$\mathrm{SA}=\|\mathrm{p} 1, \mathrm{p} 2, \ldots, \mathrm{pm}\|$,

while Player $\boldsymbol{B}$ uses an alternative strategy:

$\mathrm{SB}=\|\mathrm{q} 1, \mathrm{q} 2, \ldots, \mathrm{qn}\|$,

then average gain (mathematical expectation) of Player $\boldsymbol{A}$ is determined by the ratio

$$
\sum_{i=1}^{m} \sum_{j=1}^{n} a_{i j} p_{i} \cdot q_{j}
$$

In the formation of alternative strategies, an assumption about the credibility and reliability of information which has been used to substantiate them is usually adopted. However, for many tasks the content of which is qualitatively new, this assumption either is not realized deliberately, or it cannot be proved at the moment of making decision. This is caused by the difficulties in providing information that can be divided into groups:

1) initial statistical information which is often insufficiently reliable, however, even if there is reliable data about the past, they may not always serve as a reliable basis for decision making;

2) part information is qualitative and cannot be quantified;

3) In practice of preparation of managerial decisions situations often arise where the necessary information can be obtained, but it is absent at the moment of decision making, because obtaining and processing are time and/or money consuming;

4) there is a large group of factors that may influence the implementation of a solution in the future, but their impact cannot be accurately predicted;

5) any scientific or technical idea contians potential possibility of different implementation patterns, and any economic impact can lead to numerous consequences.

Taking into account and avoiding all deficiencies of information support in the formation of alternative strategies at the stage of choosing a development strategy, a criterion for minimizing the antagonisms between the "players" of socioeconomic relations at an early stage of development should be provided. This will further enable the industrial company to adapt more quickly to the change of external factors of influence and to avoid losses associated with the activity.

The idea of using the opening theory in formation of the development strategy of an industrial company is impossible without representing it in the general management system of a complex socioeconomic system (Fig. 2). 
The system for managing the development of a complex socio-economic system based on the theory of "debut"

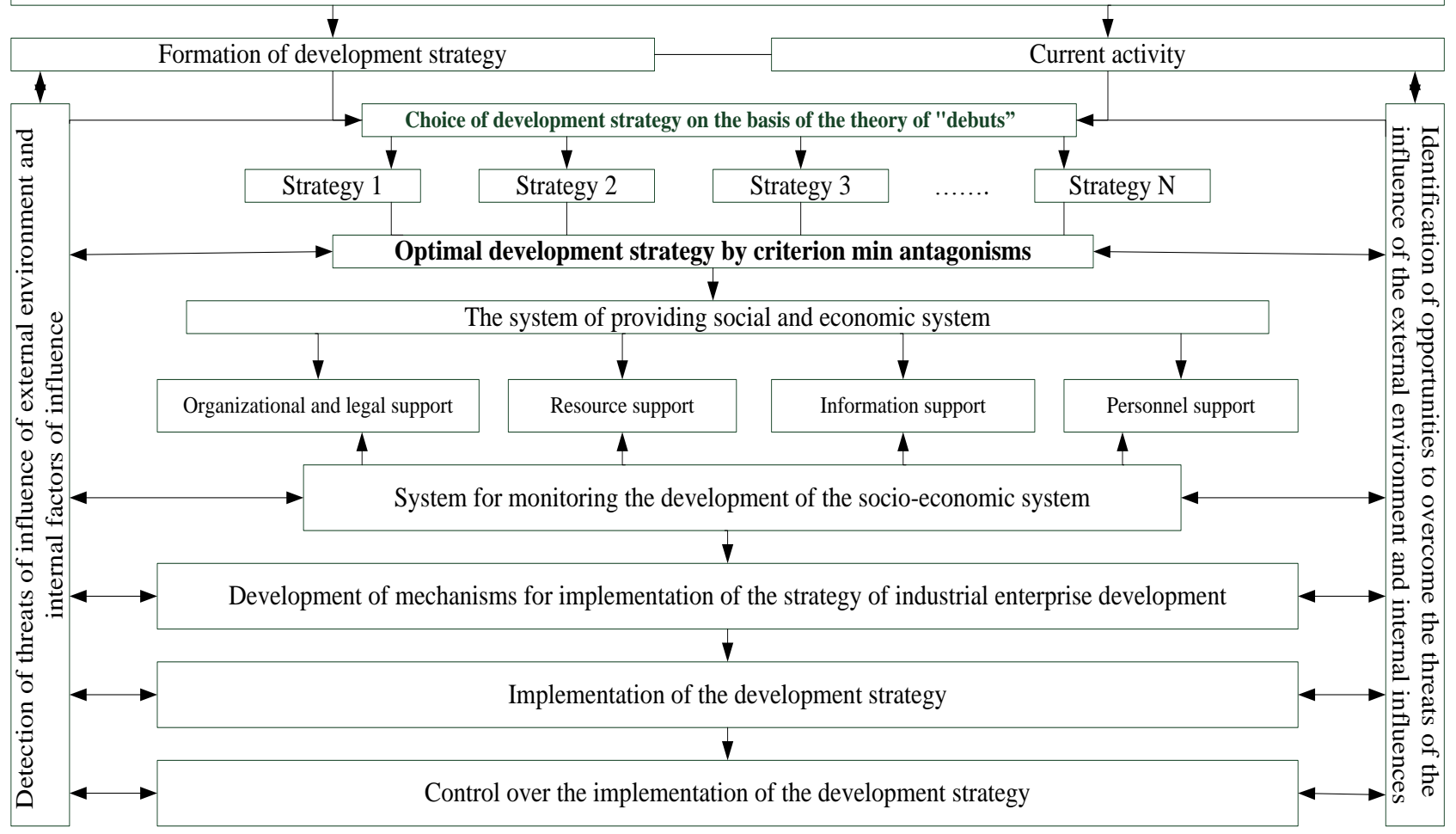

Fig. 2: Opening theory in the system of an innovative model of the development strategy of a company as a socioeconomic system

Having defined the place of the opening theory in the system of managing the development of a complex socioeconomic system, the existing management approaches should be listed: "from the achieved"; optimization; adaptive. Each of these approaches has its advantages and drawbacks.

For example, the management of an industrial company "from the achieved" is aimed at achieving a number of desired and quite feasible objectives. The starting point is the current state of the company followed by its preservation. Changes in strategy, organizational structure, etc. are considered to be undesirable, as they can spoil the established operation of the company. Any improvement of management, planning, information retrieval and analysis systems is not encouraged. This approach minimizes the costs of forming and supporting the implementation of the plan. This state of affairs is difficult to imagine in the current difficult conditions of functioning of industrial companies. Introduction of the opening theory to the management system will enable prompt adjustment to external challenges.

Optimization management is generally formed within the rational approach and is based on the use of mathematical models and methods with a view to more efficient use of resources and achievement of profit maximization and minimization of expenses and time of execution. The disadvantage of the approach is neglecting numerous qualitative and poorly formalized parameters, such as: quality, reliability, novelty of products, level of customers' satisfaction, moral environment and enthusiasm of employees, knowledge and skills portfolio of the staff. In addition, the result of the formation of optimization management does not at all take into account the initial state of the company and changes dramatically from time to time, thus causing changes in proportions, financial, information and analytical flows, organizational structure, trends of development, which in turn is also cost demanding. However, formation of the optimization management is based on work with quantitative rather than qualitative categories. As a consequence, the costs of conducting moderate and critical transformations of the company cannot be taken into account. As a result, confidence to the results of optimization management is inversely proportional to the "distance" from the initial state of the company to the calculated "optimal" state.

Adaptive management approach focuses on the process of plan formation. In this approach, everything begins with the study of the environment. Expected events are divided into three main categories: definite events, probabilistic events, indefinite events. Summarizing the analysis of the existing approaches in the management of an industrial company, it should be noted that the use of the opening theory in the management of development combines the above approaches, namely:

- elements of the optimization approach include a choice from a set of alternative strategies development, optimal with min antagonism criterion;

- "from the achieved" - taking into account positive results of the current activity using them in the formalization of the complex of parameters of socioeconomic development;

- adaptive approach in the process of formation of alternative strategies taking into account antagonisms between the parties of the socioeconomic relations, their formalization and identification of measures to avoid the probability and ambiguity of the development of events.

Thus, the opening theory which as a variant of game theory in the normal form is the main mathematical model of the management strategy for the development of a socioeconomic system, is a truly rich source of strategic scenarios that clarify the logical connections of such primary concepts as cooperative and selfish behaviour, mutual strategic expectations, tactical ambiguity and limited awareness in cooperation, exchange of threats and promises.

\section{Conclusion}

In the situation of heavy economic recession and ambiguity, the state of the national economy requires development of industrial companies with a focus on dynamic changes. A significant factor in improving the efficiency of development management of industrial companies is using innovative models of management 
strategies involving game methods, mathematical models and methods in the preparation and making of managerial decisions. At the initial stage of formation of a development strategy, companies face a number of factors which prevent them from choosing one of the best options for obtaining a positive result. That is, a number of cause-and-effect relationships occur that require formulating a few alternative scenarios of the course of events in different economic conditions, with different levels of antagonistic influence of participants of these events. Such conditions stipulate the need to use the advanced forms of innovation management for the development of industrial companies, one of which is the opening theory at the stage of formation of a development strategy.

Formation of an innovative development strategy for an industrial company on the basis of the opening theory is a complex process, which includes four stages, the most difficult of which is formalization of antagonistic relations and establishment of optimization criteria for each of them in the alternative strategies for the development of an industrial company.

Thus, the opening theory which as a variant of game theory in the normal form is the main mathematical model of the management strategy for the development of a socioeconomic system, is a truly rich source of strategic scenarios that clarify the logical connections of such primary concepts as cooperative and selfish behaviour, mutual strategic expectations, tactical ambiguity and limited awareness in cooperation, exchange of threats and promises.

\section{References}

[1] Moulin H. (1985) Game theory with examples from mathematical economy: Translated from French.M.: Mir.200 p., fig.

[2] Schumpeter J.A. (2004) The Theory of Economic Development: An Inquiry Into Profits, Capital, Credit, Interest, and the Business Cycle. Transaction Publishers New Brunswick (USA) and London (UK). 225 p.

[3] Hussler C., Pénin J., Dietrich M., Burger-Helmchen T., (2012),"Strategic management and the economics of the firm: How to reconcile the brother enemies?", Journal of Strategy and Management, Vol. 5 Iss: 4 pp. 372 - 380.

[4] Karpov A. (1990) Chess: encyclopedic dictionary. Moscow: Soviet Encyclopedia, 624 p. 